\title{
Article \\ Activity, Social Relationships, and Maternal Care in a Bottlenose Dolphin Group under Professional Care
}

\author{
Lisa K. Lauderdale * ${ }^{*}$ and Lance J. Miller \\ Chicago Zoological Society, 3300 Golf Road, Brookfield, IL 60513, USA; lance.miller@czs.org \\ * Correspondence: lisa.lauderdale@czs.org
}

check for updates

Citation: Lauderdale, L.K.; Miller, L.J. Activity, Social Relationships, and Maternal Care in a Bottlenose Dolphin Group under Professional Care. J. Zool. Bot. Gard. 2021, 2, 273-286. https://doi.org/10.3390/ jzbg2020019

Academic Editor: Steven Monfort

Received: 30 April 2021

Accepted: 25 May 2021

Published: 28 May 2021

Publisher's Note: MDPI stays neutral with regard to jurisdictional claims in published maps and institutional affiliations.

Copyright: (c) 2021 by the authors. Licensee MDPI, Basel, Switzerland. This article is an open access article distributed under the terms and conditions of the Creative Commons Attribution (CC BY) license (https:// creativecommons.org/licenses/by/ $4.0 /)$.

\begin{abstract}
Defining the activity patterns and social relationships of animals can provide valuable information related to animal welfare. Bottlenose dolphins under professional care engage in a variety of social and solitary activities, which may be influenced by conspecifics, time of day, and maternal behaviors. This study examined the social, solitary, and maternal behaviors of eight dolphins at one zoological facility. Data about social and solitary behaviors, nursing occurrences, and mother-calf pair swimming were collected five days per week over a ten-month period. The simple ratio index was used to calculate association rates for all dyads. Affiliative behaviors were the dominant behavior class and all behavior categories and swim states showed temporal oscillations throughout the day. The high association values within the mother-calf dyads suggested these ties remain strong through the second and third years of life. Preferred associates remained the same for some individuals in both social group compositions, while they differed for others. However, no large reductions in associations were recorded, suggesting strong relationships in the subgroups continued when other individuals were present. Examining sociality and activity levels may be a useful tool in continuing to improve welfare as they may be related to social groupings and environmental factors.
\end{abstract}

Keywords: bottlenose dolphin; social relationships; activity; maternal care; welfare; zoo; social behavior

\section{Introduction}

The bottlenose dolphin (Tursiops truncatus; henceforth 'dolphin') is a social species that lives in fission-fusion societies [1,2] and can develop long-term associations between individuals [3-8]. Under professional care, dolphins engage in a variety of social and solitary activities, which vary due to factors including, but not limited to, the time of day, the composition of the group, and age [9-12]. However, less is known about the relationships between adult female dolphins as well as the maternal care and behavior of dependent juveniles. Observing behavioral and association patterns can be used to inform management decisions regarding the animals' environments, social groups, health, and husbandry practices [13-15].

Various factors must be considered when evaluating these patterns, including temporal oscillations in behavior changes. Specifically, dolphins engage in more social, sexual, and play behaviors in the mornings and early afternoons when compared with the late afternoons [16-19]. In addition, dolphins under professional care are more active during the day than at night $[12,20]$. During the day, dolphins spend the majority of their time engaging in low intensity swimming, low intensity playing, and social play [12]. In cetaceans, affiliative behaviors, such as social play, rubbing, and synchronous swimming, are considered behaviors indicative of positive welfare $[9,21-24]$. In addition, social play behaviors are inversely related to agonistic behaviors [18], which are reported to occur at relatively low rates under professional care $[25,26]$.

Group composition is another important factor that may influence association patterns and activity levels. Dolphin calves and juveniles may influence both the social 
activities and behavioral patterns not only of their mother but of the entire social group. Dolphins have prolonged nursing and association periods, which can last up to three to six years $[1,5,7,27,28]$ and generally follow a pattern of very high levels of care at birth with a slow decline in maternal care over several years as the offspring gain independence [29-32]. Similarly, the rate of nursing decreases as calves age [29,32,33].

Despite the extended association and nursing period, research examining the influence of juveniles on social groups under professional care is limited. Mother-calf dyads spend between 24.67 and $65.28 \%$ of their time together during the calves' first year of life [30] and the association between dyads remains at a lower yet stable rate in years two and three of life [34]. During the first year of life, affiliative behaviors are reported between the calf and adult females, often in the form of allomaternal care, as well as with adult males $[25,34,35]$. Calf play behavior also becomes increasingly social during the first year of life [10]. Initially, the calf's mother is their primary play partner, followed by calves of a similar age. Towards the end of their first year of life, age appears to become less relevant in selecting a play partner. Thus, it is possible that dolphin calves diversify the behavior of the adults similarly to the way in which beluga calves increase play behavior in adults [24].

Regardless of the extensive knowledge of general activity patterns and the maternal care of calves, little research has focused on the impact juveniles have on the overarching social relationships and activity throughout the day over an extended period of time. The aim of the current study was to examine the activity, relationship strength, and maternal care in an established group of dolphins. Specifically, this study examined: (1) the temporality of social and solitary activities of social groups with and without dependent juveniles; (2) the association patterns relative to group composition; and (3) age-related changes in mother-calf interactions over time. The results from this study provided valuable insights for animal care professionals to make informed decisions on group housing management that can optimize the welfare of all group members based on their individual needs.

\section{Materials and Methods}

Data were collected from eight dolphins living at Brookfield Zoo in Brookfield, IL, USA. Behavioral observations of this group were collected over a ten-month period. The group consisted of two adult females and their dependent juveniles (mother-calf dyads were D7/D5 and D8/D6), one adult female (D4), two sub-adult females (D2 and D3), and one juvenile (D1) (Table 1). The habitat consisted of four interconnected areas that could be cordoned off. This allowed the dolphins either to have access to all other individuals while in one large group or to be cared for in subgroups while the dolphins only had direct access to a subset of the other individuals. During the present study, dolphins were regularly maintained in two subgroups with fixed members. One subgroup consisted of the two mother-calf dyads and the other subgroup was comprised of the remaining four dolphins. As other social configurations were rare, those data were excluded from the analysis because there was too little data to analyze.

Table 1. Participant demographic information.

\begin{tabular}{cccc}
\hline Dolphin & Age & Sex & Sub-Group \\
\hline D1 & 2 & Male & A \\
D2 & 11 & Female & A \\
D3 & 13 & Female & A \\
D4 & 14 & Female & A \\
D5 & 1 & Female & B \\
D6 & 2 & Male & B \\
D7 & 30 & Female & B \\
D8 & 34 & Female & \\
\hline
\end{tabular}

Note: The listed age was the individual's age at the beginning of data collection.

Although the offspring are classified as juveniles [36], the term mother-calf dyad will be used to denote their dependent status and continued nursing. Figure 1 depicts the 
timeline for dolphins entering and being born into the focal group. D8 gave birth to D3 (13 years), D2 (11 years), and D6 (two and a half years), prior to the data collection. D4, an unrelated female, was introduced to D2, D3, and D8 six years prior to the data collection period. D7 was introduced to the group three and a half years before data collection. D1 was born to D4 two and a half years prior to the data collection period. At that time, D4 failed to engage in maternal behaviors and D1 was hand-raised by the animal care staff at Brookfield Zoo. Therefore, D4 and D1 were not considered a mother-calf dyad in the current study. Finally, D7 gave birth to D5 one and a half years before the data collection period.

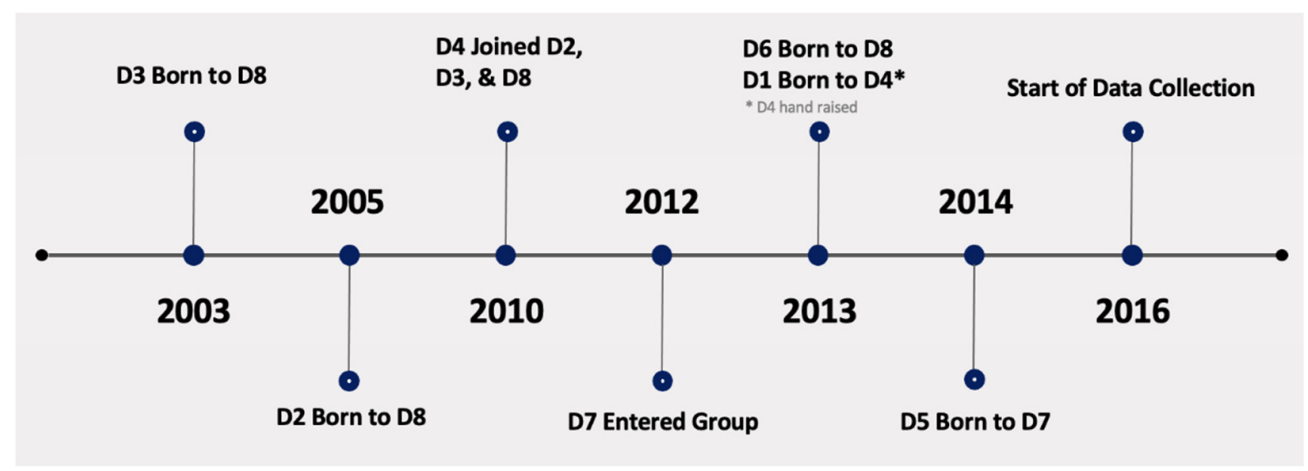

Figure 1. Timeline of dolphins entering and being born into the social group.

Both D5 and D6 were nursing and receiving fish as part of their diet at the onset of data collection. The dolphin's habitat consisted of four interconnected areas: an oblong front area $(33.5 \times 12.2 \times 6.7 \mathrm{~m}$; length $\times$ width $\times$ depth $)$, two circular rear areas $(10.7 \times 4.3 \mathrm{~m}$; diameter $\times$ depth), and a medical area $(7.6 \times 2.4 \mathrm{~m}$; diameter $\times$ depth).

Behavioral observations were recorded $18 \mathrm{~h}$ per week on a randomized, counterbalanced schedule. Direct observations were collected five days a week between 0630 and $1800 \mathrm{~h}$ local time from underwater viewing windows. Data were not collected during formal presentations or training sessions. Behavioral data were gathered in $15 \mathrm{~min}$ focal follows using the iOS mobile application Animal Behaviour Pro. Behavioral events were recorded using continuous sampling, and swim state was recorded using instantaneous sampling at $60 \mathrm{~s}$ intervals. The identification of each dolphin in the group swim was recorded at social swim state sample points. To be classified as a member of a social swim, the individual was required to be swimming synchronously with or interacting with at least one other dolphin (i.e., not in brief proximity). Behavior events, swim states and locations are operationally defined and categorized in Table S1 (Supplementary Materials). Operational definitions were adapted, in part, from Dudzinski [37], Harvey [38], and Hill and colleagues [23].

Reliability was calculated using a combination of live observations and video recordings. Inter-observer agreement was evaluated for 16 live observations $(4 \mathrm{~h})$. Intra-observer reliability was evaluated through scoring three one-hour video observations three times over the data collection periods. Reliability was calculated with Pearson's correlation coefficient and Cohen's kappa for continuous and instantaneous data [39]. At least 80\% reliability was achieved for inter- and intra-reliability. All behavioral data were collected by the first author.

Data were analyzed and graphed using IBM SPSS Statistics 21, Microsoft Excel (version 16), and Gephi (version 0.9.2). Non-parametric statistics were used due to the small sample size, and differences were considered significant at $p<0.05$. Data were partitioned into groups of nine consecutive observations in order to create blocks of data. In total, there were 42 blocks of data (collected over 10 months) grouped into three phases based on availability of a novel enrichment device. The novel enrichment device was a submerged clear box with a shelf that lowered to release a food reward when a specific amount of weight was added (see Lauderdale and Miller [40] and Lauderdale \& Miller [41] for details). 
Phase 1 included the 12 blocks of data collected prior to the introduction of the novel enrichment device. Phase 2 included the subsequent 18 blocks of data during which the dolphins had access to the novel enrichment device once per day, five days per week between 1200 and $1300 \mathrm{~h}$, when observations were not being collected. Phase 3 included the following 12 blocks of data when the dolphins no longer had access to the novel enrichment device. To assess swim types from the instantaneous samples, the average amount of time spent in each swim state (solo swim and social swim) for each block was calculated by summing the number of occurrences in each category and dividing by the total number of visible scans for each dolphin. To assess behavior events from the continuous samples, the rates of behavior in each category (i.e., social active, social agonistic, social sexual, and solitary active) were calculated by summing the number of events by the total number of minutes visible.

The rate for each behavior and swim type was averaged in the early morning (0600-0829 h), late morning (0830-1145 h), and afternoon (1315-1630 h) and then plotted based on time of day. Generalized estimating equations were used to determine if swim type and behavior categories were affected by time of day. These predictive models allowed for the individual dolphin to be the unit of analysis and the repeated measurement on an individual. Univariate regression models were built with an independent correlation structure for solo swim, social swim, social active, social agonistic, social sexual, and solitary active behaviors.

The simple ratio index [42] was used to calculate association rates for all dyads in the group. High association indices indicate a stronger tie between the two individuals. To illustrate social structure within the group and each subgroup, dyadic relationships were displayed visually. Changes in association indices over time were examined using chronological randomization tests [43,44]. Data were parsed into three time periods, which aligned with the implementation of a complex environmental enrichment device (see $[40,41]$ for details).

The rate of nursing for mother-calf pairs was calculated by summing the number of nursing occurrences by the number of minutes visible and was plotted over time. The percentage of time mother-calf dyads spent together was calculated by summing the number of events in a pair or social swim by the number of minutes visible and was plotted over time.

\section{Results}

\subsection{Activity}

Dolphins spent an average of $45.30 \%$ of their time in solo swims and $54.58 \%$ of their time in social swims (Table 2). D1, D2, D3, and D4 spent the largest portion of their time in solo swims. D5, D6, D7, and D8 spent the largest portion of their time in social swims.

Table 2. Percentage of time spent in social and solo swim states.

\begin{tabular}{ccc}
\hline Dolphin & Solo Swim & Social Swim \\
\hline D1 & 67.63 & 32.36 \\
D2 & 67.78 & 32.22 \\
D3 & 60.36 & 39.65 \\
D4 & 64.65 & 35.35 \\
D5 & 24.84 & 75.15 \\
D6 & 22.45 & 77.56 \\
D7 & 31.25 & 68.75 \\
D8 & 31.86 & 68.13 \\
\hline
\end{tabular}

The average rate of social active behaviors was 0.55 per minute visible. The young males, D1 and D6, engaged in almost twice as many social active behaviors as the other dolphins (Table 3). Social agonistic behaviors were rarely observed with an average rate of 0.01 . Social sexual behaviors were also seldomly observed, especially among adults and subadults, with an average rate of 0.03 per minute visible. Solitary active behaviors were observed at a rate of 0.28 per minute visible. 
Table 3. Rates of behaviors in the social active, social agonistic, social sexual, and solitary active categories.

\begin{tabular}{ccccc}
\hline Dolphin & Social Active & Social Agonistic & Social Sexual & Solitary Active \\
\hline D1 & 1.05 & 0.02 & 0.07 & 0.49 \\
D2 & 0.47 & 0.01 & 0.01 & 0.26 \\
D3 & 0.30 & 0.01 & 0.01 & 0.25 \\
D4 & 0.47 & 0.01 & 0.01 & 0.25 \\
D5 & 0.57 & 0.01 & 0.03 & 0.33 \\
D6 & 1.14 & 0.02 & 0.06 & 0.27 \\
D7 & 0.25 & 0.01 & 0.01 & 0.16 \\
D8 & 0.45 & $<0.01$ & 0.03 & 0.30 \\
\hline
\end{tabular}

Behaviors and swim types associated with the time of day were evaluated. Time of day was significant for all behavior categories (Table 4). The models showed solo swims were more common in the late morning and afternoon than in the early morning and social swims were less common in the late morning and afternoon than in the early morning. Social active behaviors decreased in the afternoon when compared with the early morning. Social agonistic behaviors were increased in the afternoon when compared with the early morning. Social sexual behaviors decreased in the afternoon when compared with the early morning. Solitary active behaviors increased in the late morning and afternoon when compared with the early morning.

Table 4. Results for models examining behavior and swim type categories.

\begin{tabular}{|c|c|c|c|c|c|c|}
\hline Predictor & Response & Beta & $\begin{array}{l}\text { Std. } \\
\text { Error }\end{array}$ & $\begin{array}{c}\text { Lower } \\
95 \% \text { CI }\end{array}$ & $\begin{array}{c}\text { Upper } \\
95 \% \text { CI }\end{array}$ & $p$ Value \\
\hline \multirow{4}{*}{ Solo Swim } & (Intercept) & 0.324 & 0.072 & 0.182 & 0.465 & $<0.001$ \\
\hline & Early Morning & - & - & - & - & - \\
\hline & Late Morning & 0.140 & 0.019 & 0.103 & 0.177 & $<0.001^{*}$ \\
\hline & Afternoon & 0.245 & 0.024 & 0.197 & 0.293 & $<0.001$ * \\
\hline \multirow{4}{*}{ Social Swim } & (Intercept) & 0.676 & 0.072 & 0.535 & 0.818 & $<0.001$ \\
\hline & Early Morning & - & - & - & - & - \\
\hline & Late Morning & -0.140 & 0.019 & -0.177 & -0.103 & $<0.001$ * \\
\hline & Afternoon & -0.250 & 0.025 & -0.299 & -0.201 & $<0.001$ * \\
\hline \multirow[t]{2}{*}{ Social } & (Intercept) & 0.559 & 0.106 & 0.351 & 0.767 & $<0.001$ \\
\hline & Early Morning & - & - & - & - & - \\
\hline \multirow[t]{2}{*}{ Active } & Late Morning & 0.019 & 0.026 & -0.032 & 0.070 & 0.470 \\
\hline & Afternoon & -0.050 & 0.018 & -0.085 & -0.015 & $0.006^{*}$ \\
\hline \multirow[t]{2}{*}{ Social } & (Intercept) & 0.006 & 0.003 & 0.001 & 0.011 & 0.011 \\
\hline & Early Morning & - & - & - & - & - \\
\hline \multirow[t]{2}{*}{ Agonistic } & Late Morning & 0.004 & 0.003 & -0.002 & 0.010 & 0.216 \\
\hline & Afternoon & 0.006 & 0.003 & 0.001 & 0.011 & 0.011 * \\
\hline \multirow[t]{2}{*}{ Social } & (Intercept) & 0.043 & 0.014 & 0.015 & 0.070 & 0.003 \\
\hline & Early Morning & - & - & - & - & - \\
\hline \multirow[t]{2}{*}{ Sexual } & Late Morning & -0.013 & 0.008 & -0.028 & 0.003 & 0.112 \\
\hline & Afternoon & -0.028 & 0.010 & -0.048 & -0.007 & 0.007 * \\
\hline \multirow[t]{2}{*}{ Solitary } & (Intercept) & 0.155 & 0.018 & 0.120 & 0.190 & $<0.001$ \\
\hline & Early Morning & - & - & - & - & - \\
\hline \multirow[t]{2}{*}{ Active } & Late Morning & 0.150 & 0.025 & 0.102 & 0.198 & $<0.001$ * \\
\hline & Afternoon & 0.224 & 0.042 & 0.141 & 0.306 & $<0.001$ * \\
\hline
\end{tabular}




\subsection{Dyadic Relationships}

Participants were in a single group for $45.20 \%$ of the observations and were in subgroups for the remaining observations. Subgroup A (comprised of D1, D2, D3, and D4) were together for $18.29 \%$ of observations. Subgroup B (comprised of D5, D6, D7, and D8) were together for $19.19 \%$ of the observations. In the remaining $17.32 \%$ of observations, dolphins were in various subgroups of two to six dolphins and data were excluded from the analyses. The mean difference of the simple ratio index values from the chronological randomization tests are given in Table 5. The tests showed there were no significant differences in relationship strength between neither Phase 1 and 2 nor Phase 2 and 3.

Table 5. Mean difference for the simple ratio index (SRI) values between Phase 1 and 2 and Phase 2 and 3.

\begin{tabular}{cccccc}
\hline Dyad & SRI Phase 1 and 2 & SRI Phase 2 and 3 & Dyad & SRI Phase 1 and 2 & SRI Phase 2 and 3 \\
\hline D1/D2 & -0.01 & -0.02 & D3/D5 & 0.03 & -0.03 \\
D1/D3 & 0.01 & 0.00 & D3/D6 & -0.04 & -0.01 \\
D1/D4 & 0.03 & 0.02 & D3/D7 & 0.03 & -0.02 \\
D1/D5 & 0.04 & -0.03 & D3/D8 & -0.06 & -0.03 \\
D1/D6 & -0.04 & -0.02 & D4/D5 & 0.02 & -0.02 \\
D1/D7 & 0.01 & -0.01 & D4/D6 & -0.01 & -0.04 \\
D1/D8 & 0.01 & 0.01 & D4/D7 & 0.02 & -0.03 \\
D2/D3 & 0.03 & -0.05 & D4/D8 & -0.14 & -0.09 \\
D2/D4 & 0.00 & -0.05 & D5/D6 & 0.05 & 0.01 \\
D2/D5 & 0.01 & -0.01 & D5/D7 & 0.00 & 0.08 \\
D2/D6 & -0.03 & 0.03 & D5/D8 & 0.04 & -0.04 \\
D2/D7 & 0.01 & -0.01 & D6/D7 & 0.04 & -0.03 \\
D2/D8 & 0.01 & 0.04 & D6/D8 & 0.20 & 0.00 \\
D3/D4 & 0.06 & -0.14 & D7/D8 & 0.06 & -0.05 \\
\hline
\end{tabular}

Note: Negative numbers indicate a decrease in relationship strength and positive numbers indicate an increase in relationship strength.

All dolphins associated with other group and subgroup members (Figure 2). The high association values within the mother-calf dyads suggested these ties remained very strong through the third and fourth years of life within this group. D8 had high association values with her other offspring, D2 and D3, when all dolphins were together. The three siblings (D2, D3, and D6) also had high association values when all dolphins were together. D5 and D7 (a mother-calf dyad) had the highest association value. D7 and D2 as well as D7 and D1 had the lowest association values. When D5, D6, D7, and D8 were in a subgroup, both mother-calf dyads had high association values, with D5 and D7 associating the most. When D1, D2, D3, and D4 were in a subgroup, D2 and D3 had the highest association value and D1 and D3 had the lowest association value.

\subsection{Maternal Care}

There were two nursing mother-calf dyads in the focal group. D8's offspring, D6, was two and a half years old and D7's offspring, D5, was one and a half years old. Both juveniles were regularly nursing at the onset of data collection and rarely nursed by the end of the data collection (Figure 3). On average, D6 nursed at a rate of 0.08, and D5 nursed at a rate of 0.04 . When the rate of nursing was plotted over time, Figure 3 suggested D6 nursed at a more variable rate than D5. In addition, D6 also nursed at a higher rate between blocks 6 and 22 despite being older than D5. 


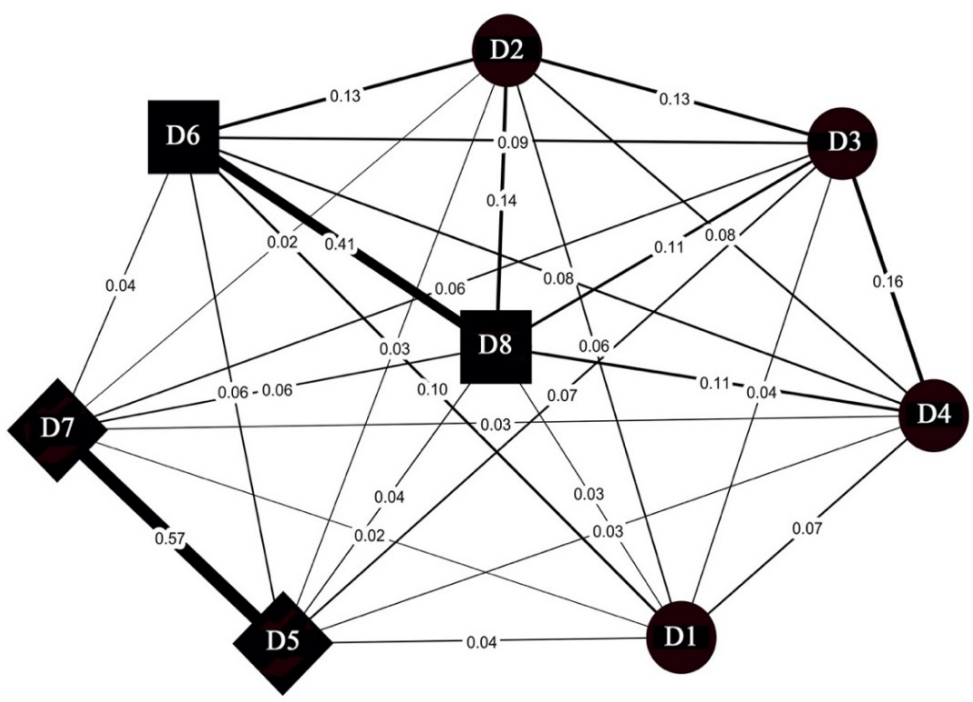

(a)

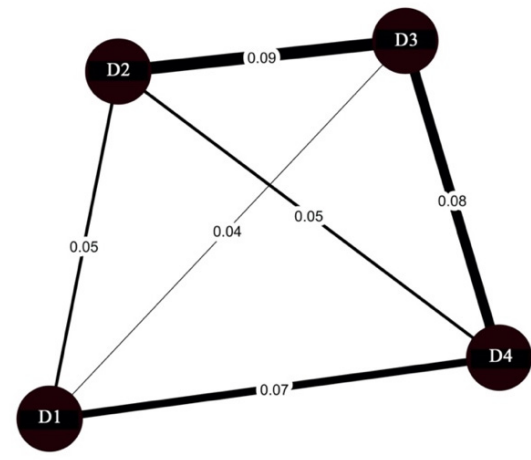

(b)

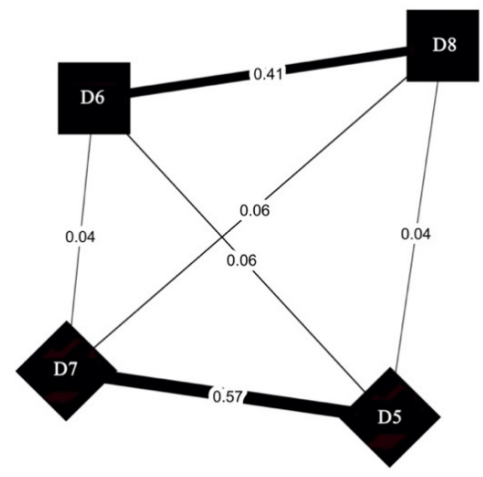

(c)

Figure 2. Three networks for dolphins in various groups. Thicker lines (edges) indicate a stronger tie between the two individuals (nodes). Mother-calf dyads are indicated by matching square nodes and diamond nodes. Individuals not part of a mother-calf dyad are indicated by circles. (a) Network representing time periods when all eight dolphins were accessible to each other. (b) Network representing time periods when D1, D2, D3, and D4 were separated as a subgroup. (c) Network representing time periods when D5, D6, D7, and D8 were separated as a subgroup.

Rate of Nursing

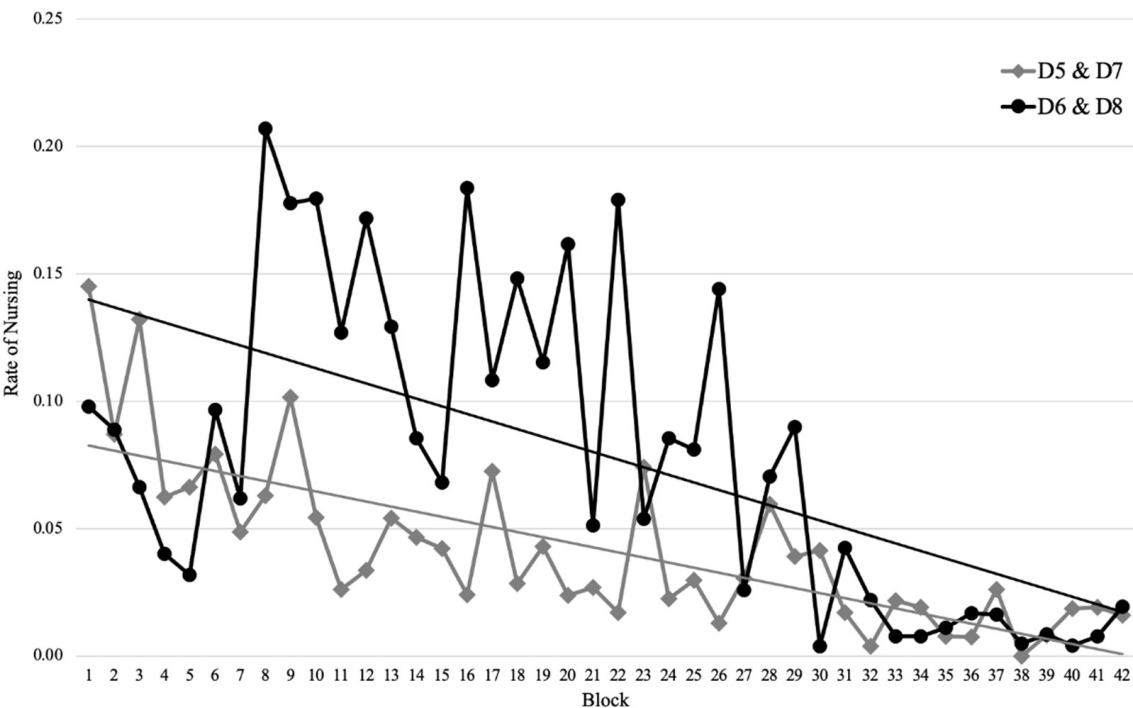

Figure 3. Rates of nursing over the 10-month observation period. 
On average, D7 and D5 spent 55.11\% of their time together, and D8 and D6 spent $40.74 \%$ of their time swimming as a mother-calf dyad. Figure 4 suggested the percentage of time spent swimming as a dyad remained relatively stable over a ten-month period for both mother-calf dyads. The rates of nursing and swimming as a dyad were not statistically compared because D6 was one year older than D5.

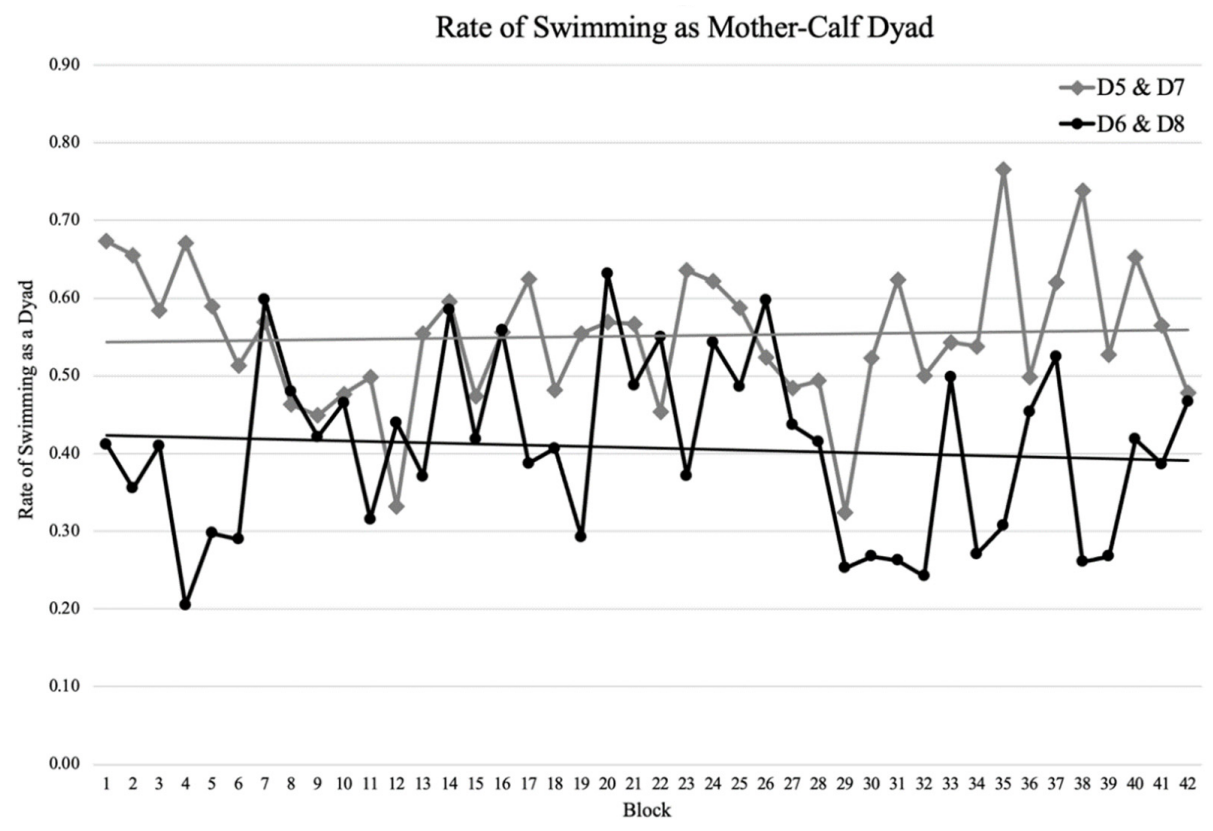

Figure 4. Rates of pair swimming of the two mother-calf dyads over the 10-month observation period.

\section{Discussion}

The current study explored the activity levels, social relationships, and maternal care of juveniles in a group of dolphins under professional care.

\subsection{Activity}

The activity budget showed individuals that were part of a mother-calf dyad spent most of their time in social swims (72.4\%) and other individuals spent most of their time in solo swims (65.1\%). These findings are consistent with prior reports that showed high rates of association between mother-calf pairs [30]. Social swimming and play behaviors of nonmother-calf dyads are estimated to account for anywhere between $12.43 \%$ and $42.12 \%$ of a dolphin's time under professional care [12,45]. In line with these reports, the dolphins not in mother-calf dyads in the present study spent an average of $34.9 \%$ of their time in social swims. The most common type of behavior each dolphin engaged in were social active behaviors. Though dolphins of all ages participate in play and social behaviors, calves and juvenile dolphins engage in more play behaviors and initiated more social interactions than adult dolphins $[10,46,47]$. The dolphin group in the present study included three juveniles, which likely contributed to the number of social behaviors observed.

The dolphins rarely engaged in agonistic encounters or social sexual behaviors. The low rates of sexual and agonistic behaviors may be due to the fact that there were no adult males in the group. Adult males typically engage in the most agonistic encounters [26]. The low rates of agonism in the present study were comparable to those previously reported for other groups of dolphins under professional care $[25,26]$. Previously, agonistic behaviors in the group of dolphins (which included both D7 and D8 from the present study) at Brookfield Zoo were examined in 1991 [26]. Adult males had higher rates of aggressive behavior and females had a stable dominance hierarchy related to age. While the males in the present group were still juveniles, they engaged in the most agonistic encounters (at a rate of 0.02 ), which was similar to the rates previously reported for subadult and 
adult males [26]. This suggests the sex differences in agonistic behavior may begin at a young age.

There was a pattern of lower rates of agonistic behavior of females, which suggested a stable dominance hierarchy similar to the one reported by Samuels and Gifford [26]. Of the females, D7 had the highest rate of agonistic behavior. Early in calves' life, mother dolphins serve in a protective role to guard their calves from potential threats, including other dolphins [29-31,48]. D7's rate of aggression might be related to protecting her calf. D7 also exhibited the least amount of social active behaviors, which is consistent with previous findings that social play behaviors are inversely related to agonistic behaviors [18].

All behavior and swim types were impacted by the time of day. Solo swimming, solitary active behaviors, and agonistic behaviors were more common in the afternoon when compared with the early morning. The dolphins exhibited more social active and sexual behaviors in the early morning than in the afternoon. Previous reports detail similar findings that dolphins and whales under professional care engage in more social, sexual, and play behaviors in the morning than in the afternoon [16-19], in the early afternoon than in the late afternoon [49], and during the day than at night [12]. As activity levels and social behaviors are used as a component of welfare assessments [19,50], incorporating the potential effects of time of day on dolphin behavior is important for developing methods that accurately assess an individual's or group's welfare.

\subsection{Dyadic Relationships}

The relationships found within this group highlighted a range of association rates. None of the association rates for any of the dyads reduced when in the larger group, suggesting the dolphins were not avoiding subgroup mates when in the larger group. All dyads were observed associating during the study period.

Mother-calf bonds are the strongest type of association for dolphins [7,51]. In the wild, mothers and calves maintain a rich social network with other dolphins throughout the calves' dependency period [51-53]. Wild dolphin calves are exposed to a large number of associates through their mothers' associations [52]. In the present study, mother-calf dyads remained each other's primary associates, whether they were in the subgroup or the larger group. Further, they regularly associated with the other members of the larger group.

Other than her mother, D5's primary associate in her subgroup was D6, the male juvenile. Her primary associate was D3 in the larger group, and the association with D6 continued to be strong. Other than his mother, D6's primary associate in the subgroup was D5. His primary associate in the larger group was D2. D6 appeared to be a wellconnected individual with ties above 0.08 to both related and unrelated females, specifically D1, D2, D3, and D4. It is feasible these relationships were an artifact of his mother's association strengths with those individuals, as both D5 and D7 had association indices 0.07 or lower with the other non-maternal sub-adult/adult female dolphins. Consistently, wild calves whose mothers spend more time in groups have more associates [52]. Another potential contributing factor to the difference in sociality of D5 and D6 was the one-year age difference, which may have resulted in higher independence and sociality for the older juvenile. Previous research suggests calves become more independent as they age, and mothers begin to engage in more passive forms of maternal control [30]. Similarly, D5 and D7's association value suggested they spent more time together than D6 and D8 did.

D1 was hand raised by the animal care staff. His association values suggested he did not have a traditional maternal figure similar to the other juveniles. D1's primary associate changed from D4 to D6 in the larger group, which suggests he may have sought out a conspecific of the same sex and a similar age when one was available. Previous findings showed conspecifics of the same sex and a similar age are preferred play partners and young males prefer juvenile and adult male conspecifics $[10,52,54]$.

Kinship in females is an important correlate to associations in many species [55-57]. In Shark Bay, Western Australia, female dolphins continue to regularly associate with their mother after she had another calf [5]. Bands of wild dolphins in Sarasota Bay are often 
composed of female relatives [8,58]. In wild Indo-Pacific bottlenose dolphins off the coast of southeastern Australia, frequent female associates have higher genetic relatedness than infrequent associates [59]. However, kinship relations were not found to be a requirement for membership within these social clusters. Dolphins in the present study showed a similar structure, where D8 and her daughters (i.e., D2 and D3) remained as relatively frequent associates alongside D4, who was an unrelated female. As the association strength of D8 and her offspring were similar to the association strength between her and D4, D2 and D3 may be preferred associates but fully independent individuals.

\subsection{Maternal Care}

Both mothers in the current study still engaged in maternal behaviors and regularly associated with their juvenile offspring. Two features of maternal care were examined: percentage of time spent swimming as a mother-calf dyad and rate of nursing. Dolphins have prolonged nursing and association periods that can last up to 3 to 6 years $[1,5,7,27]$. However, the majority of previous research of maternal care in dolphins under professional care has focused on the characteristics of maternal care for calves less than one year old $[29,30,32]$.

Previous research suggests a similar pattern of very high levels of care at birth with a slow decline in maternal care over several years as the calves gain independence [29-32]. Gubbins and colleagues [29] reported association strength decreased over the first year of life but began to stabilize around 37 weeks of age. Hill and colleagues [30] reported the average rate of mother-calf swimming together between $24.67 \%$ and $65.28 \%$ of the time during the calves' first years of life. Mann and colleagues [60] found association rates in mother-calf dyads remained stable in the second and third years of life. Consistently, the juveniles in the present study (age one and half and two and a half years old at the onset of the study) had relatively steady rates of mother-calf dyad swimming over the ten-month data collection period. The older juvenile in this study was more independent and spent approximately $10 \%$ less time with its mother than the younger juvenile. This suggests there may be rapid development in the first year, which results in gaining independence quickly and slows as calves age past the first year.

Both juveniles in the mother-calf dyads continued to nurse throughout the data collection period. The results were consistent with the previously reported trend of nursing decreasing as the calves age $[29,32,33]$. At the beginning of the study, both offspring nursed a rate similar to previous reports of calves between the ages of nine weeks and five months $[32,61]$. However, previous reports used scan sampling rather than continuous sampling as used here; therefore, prior nursing rates might be underreported. Unexpectedly, D6's average nursing rate was higher than D5's nursing rate despite him being a year older. Yet, both juveniles had similar and relatively low rates of nursing throughout the last quarter of the study. This suggests individual differences in maternal care and/or offspring personality may play a large role in the time frame in which nursing is reduced.

While the general strategies of maternal care are similar in dolphins, mothers exhibit individual differences in some aspects of the care of their calves and adapt their level of control to the calves' age and social environment [30]. Presumably, individual differences in maternal style moderated the dyad swimming rates and nursing rates as these offspring got older. In addition, the mothers likely monitored and mediated the number and identity of other participants in their offspring's social interactions.

\subsection{Limitations}

The association indices are inclusive of affiliative, neutral, and agonistic interactions. However, the results of the social analyses are discussed with the frame of reference that interactions were overall positive and mutual, evidenced by the extremely low levels of agonistic behavior in the group. In addition, the behavior of dolphins under professional care is modulated by trainer interactions including training sessions and the enrichment they provide [62]. In the present study, the majority of training sessions and enrichment 
occurred during the late morning and afternoon time periods. Thus, they may have influenced association patterns and activities during those time periods. The zoo habitat may have resulted in the potential that false social associations were recorded based on proximity. However, the definitions used to record social behaviors excluded events in which dolphins were only in brief proximity and were not interacting, thereby reducing the likelihood that false associations would be included in the data set.

In addition, dolphins had access to a complex cognitive enrichment apparatus (see Lauderdale and Miller [40] for details) for one hour a day, five days per week between blocks 12 and 30 of the data collection period. As a group, the dolphins participated in significantly more social swims during these blocks than in the blocks before or after interacting with the enrichment apparatus [41]. Specifically, D5 and D8 interacted with the apparatus simultaneously and swam together significantly more often during these blocks. D5 also engaged in significantly more social active and solitary active behaviors. Therefore, D5 and D8's association index value and D5's rate of social active and solitary active behaviors in the present study were higher as a result of the enrichment apparatus.

\section{Conclusions}

Affiliative behaviors were the dominant behavior class in this social group. All behavior and swim states differed based on the time of day. The time of day affected both sociality and behavior. Preferred associates remained the same for some individuals in the subgroup as in the larger group, while they differed for other individuals. However, no large reductions in associations were recorded suggesting dyads with strong relationships in the subgroups continued to associate when other individuals were accessible. Bonds between mother and calf in dyads remained very strong in both the subgroup and the larger group. However, differences in maternal style also may have moderated the strength of other social relationships. Positive social relationships can enhance the welfare of dolphins under professional care $[50,63]$. Social behaviors, such as synchronous swimming, are associated with positive affective states [64]. Therefore, measuring dolphin's social behavior and defining the strengths of relationships may provide insight into an individual's welfare state as social behaviors appear to be related to sex, environmental enrichment factors (i.e., enrichment schedule and frequency of new enrichment), and social grouping [19,41].

This type of information can be incorporated into the daily management of the dolphins. The present study acts as a baseline for rates of social and solitary swimming for these individuals and could be used as one component of their continuous welfare monitoring program. These data could be used to assess the effectiveness of enrichment designed to promote social behaviors. In addition, data on pair swimming and agonistic behavior could speak to the cohesiveness of the group and influence the composition of subgroups. For example, two animals with high association values could be managed in the same subgroup more often. Finally, the information on maternal care could be valuable to monitoring the dependence and social development of juveniles. Examining key aspects of sociality over time (i.e., strength of relationships and rates of play, pair swimming, and agonistic behavior) and activity levels may be important predictors of welfare. Sociality and activity appear to be related to the composition of the social group and the time of day. Therefore, they may be a useful tool in monitoring and continuing to improve welfare.

Supplementary Materials: The following are available online at https:/ / www.mdpi.com/article/10 .3390/jzbg2020019/s1, Table S1: Swim State Operational Definitions, Behavior Event Operational Definitions.

Author Contributions: Each author made substantial contributions to generating this manuscript. Conceptualization, L.K.L. and L.J.M.; methodology, L.K.L. and L.J.M.; validation, L.K.L. and L.J.M.; formal analysis, L.K.L.; investigation, L.K.L.; resources, L.K.L. and L.J.M.; data curation, L.K.L.; writing—original draft preparation, L.K.L.; writing—review and editing, L.K.L. and L.J.M.; visualization, L.K.L.; supervision, L.J.M.; project administration, L.K.L. All authors have read and agreed to the published version of the manuscript. 
Funding: This research received no external funding.

Institutional Review Board Statement: The study was approved by the Institutional Animal Care and Use Committee of University of Southern Mississippi (protocol number 16052607).

Data Availability Statement: The data presented in this study are available on reasonable request from the corresponding author.

Acknowledgments: The authors would like to thank Sarah Breen-Bartecki and Bill Ziegler for their support of this project. In addition, we are grateful to Rita Stacey and the Seven Seas animal care specialists for their assistance and support.

Conflicts of Interest: The authors declare no conflict of interest.

\section{References}

1. Connor, R.C.; Wells, R.S.; Mann, J.; Read, A.J. The bottlenose dolphin: Social relationships in a fission-fusion society. In Cetacean Societies: Field Studies of Dolphins and Whales, 1st ed.; Mann, J., Connor, R., Tyack, P., Whitehead, H., Eds.; The University of Chicago Press: Chicago, IL, USA, 2000; pp. 91-126.

2. Gowans, S.; Würsig, B.; Karczmarski, L. The Social Structure and Strategies of Delphinids: Predictions Based on an Ecological Framework. Adv. Mar. Biol. 2007, 53, 195-294. [CrossRef]

3. Bruck, J.N. Decades-long social memory in bottlenose dolphins. Proc. R. Soc. B Boil. Sci. 2013, 280, 20131726. [CrossRef]

4. Connor, R.C.; Smolker, R.A.; Richards, A.F. Two levels of alliance formation among male bottlenose dolphins (Tursiops sp.). Proc. Natl. Acad. Sci. USA 1992, 89, 987-990. [CrossRef]

5. Smolker, R.A.; Richards, A.F.; Connor, R.C.; Pepper, J.W. Sex differences in patterns of association among Indian Ocean bottlenose dolphins. Behaviour 1992, 123, 38-69. [CrossRef]

6. Tyack, P. Whistle repertoires of two bottlenosed dolphins, Tursiops truncatus: Mimicry of signature whistles? Behav. Ecol. Sociobiol. 1986, 18, 251-257. [CrossRef]

7. Wells, R.S.; Scott, M.D.; Irvine, A.B. The Social Structure of Free-Ranging Bottlenose Dolphins. In Current Mammalogy; Springer: Boston, MA, USA, 1987; pp. 247-305.

8. Wells, R.S. The role of long-term study in understanding the social structure of a bottlenose dolphin community. In Dolphin Societies: Discoveries and Puzzles, 1st ed.; Pryor, K., Norris, K., Eds.; University of California Press: Berkeley, CA, USA, 1991; pp. 199-225.

9. Kuczaj, S.A.; Makecha, R.; Trone, M.; Paulos, R.D.; Ramos, J.A. Role of peers in cultural innovation and cultural transmission: Evidence from the play of dolphin calves. Int. J. Comp. Psychol. 2006, 31, 223-240.

10. Mackey, A.; Makecha, R.; Kuczaj, S. The Development of Social Play in Bottlenose Dolphins (Tursiops truncatus). Anim. Behav. Cogn. 2014, 1, 19-35. [CrossRef]

11. Von Streit, C.; Ganslosser, U.; von Fersen, L. Behavioral development of two captive mother-calf dyads of bottlenose dolphins (Tursiops truncatus) in the calves' first year. Int. J. Comp. Psychol. 2013, 26, 176-196. [CrossRef]

12. Walker, R.T.; Miller, L.J.; Ii, S.A.K.; Solangi, M. Seasonal, Diel, and Age Differences in Activity Budgets of a Group of Bottlenose Dolphins (Tursiops truncatus) Under Professional Care. Int. J. Comp. Psychol. 2017, 30, 30. [CrossRef]

13. Carlstead, K.; Shepherdson, D. Effects of environmental enrichment on reproduction. Zoo Biol. 1994, 13, 447-458. [CrossRef]

14. McPhee, M.E.; Carlstead, K. The importance of maintaining natural behaviors in captive mammals. In Wild Mammals in Captivity: Principles and Techniques for Zoo Management, 2nd ed.; University of Chicago Press: Chicago, IL, USA, 2010; pp. $303-313$.

15. Rose, P.; Riley, L. The use of Qualitative Behavioural Assessment to zoo welfare measurement and animal husbandry change. J. Zoo Aquar. Res. 2019, 7, 150-171.

16. De Moura Lima, A. Production and Perception of Acoustic Signals in Captive Bottlenose Dolphins (Tursiops truncatus): Con-textual Use of Social Signals and Recognition of Artificial Labels. Ph.D. Thesis, Université Rennes 1, Rennes, France, 16 December 2019. Available online: https://tel.archives-ouvertes.fr/tel-02412889 (accessed on 24 March 2021).

17. Saayman, G.S.; Tayler, C.K.; Bower, D. Diurnal Activity Cycles in Captive and Free-Ranging Indian Ocean Bottlenose Dolphins (Tursiops Aduncus Ehrenburg). Behaviour 1973, 44, 212-233. [CrossRef]

18. Serres, A.; Delfour, F. Environmental changes and anthropogenic factors modulate social play in captive bottlenose dolphins (Tursiops truncatus). Zoo Biol. 2017, 36, 99-111. [CrossRef]

19. Serres, A.; Hao, Y.; Wang, D. Body Contacts and Social Interactions in Captive Odontocetes Are Influenced by the Context: An Implication for Welfare Assessment. Animals 2020, 10, 924. [CrossRef]

20. Shorter, K.A.; Shao, Y.; Ojeda, L.; Barton, K.; Rocho-Levine, J.; Van Der Hoop, J.; Moore, M. A day in the life of a dolphin: Using bio-logging tags for improved animal health and well-being. Mar. Mammal Sci. 2017, 33, 785-802. [CrossRef]

21. Clark, F.E. Marine mammal cognition and captive care: A proposal for cognitive enrichment in zoos and aquariums. J. Zoo Aquar. Res. 2013, 1, 1-6.

22. Held, S.D.; Špinka, M. Animal play and animal welfare. Anim. Behav. 2011, 81, 891-899. [CrossRef]

23. Hill, H.M.; Dietrich, S.; Yeater, D.; McKinnon, M.; Miller, M.; Aibel, S.; Dove, A. Developing a catalog of socio-sexual behaviors of beluga whales (Delphinapterus leucas). Anim. Behav. Cog. 2015, 2, 105-123. [CrossRef] 
24. Hill, H.; Guarino, S.; Crandall, S.; Lenhart, E.; Dietrich, S. Young belugas diversify adult beluga (Delphinapterus leucas) behavior. Anim. Behav. Cog. 2015, 2, 267-284. [CrossRef]

25. Eskelinen, H.C.; Borger-Turner, J.L.; Ii, S.A.K. Observations of a Paternal Male with Bottlenose Dolphin Calf (Tursiops truncatus): A Case Study. Int. J. Comp. Psychol. 2017, 30, 30. [CrossRef]

26. Samuels, A.; Gifford, T. A Quantitative Assessment of Dominance Relations among Bottlenose Dolphins. Mar. Mammal Sci. 1997, 13, 70-99. [CrossRef]

27. Mann, J.; Connor, R.C.; Barre, L.M.; Heithaus, M.R. Female reproductive success in bottlenose dolphins (Tursiops sp.): Life history, habitat, provisioning, and group-size effects. Behav. Ecol. 2000, 11, 210-219. [CrossRef]

28. Wells, R.S.; Scott, M.D. Bottlenose dolphin Tursiops truncatus (montagu, 1821). Handb. Mar. Mamm. 1999, 6, 137-182.

29. Gubbins, C.; McOwan, B.; Lynn, S.K.; Hooper, S.; Reiss, D. Mother-Infant Spatial Relations in Captive Bottlenose Dolphins, Tursiops Truncatus. Mar. Mammal Sci. 1999, 15, 751-765. [CrossRef]

30. Hill, H.M.; Greer, T.; Solangi, M.; Kuczaj, S.A. All mothers are not the same: Maternal styles in bottlenose dolphins (Tursiops truncatus). Int. J. Comp. Psychol. 2007, 20, 35-54.

31. Mann, J.; Smuts, B.B. Natal attraction: Allomaternal care and mother-infant separations in wild bottlenose dolphins. Anim. Behav. 1998, 55, 1097-1113. [CrossRef] [PubMed]

32. Reid, K.; Mann, J.; Weiner, J.R.; Hecker, N. Infant development in two aquarium bottlenose dolphins. Zoo Biol. 1995, 14, 135-147. [CrossRef]

33. McBride, A.F.; Kritzler, H. Observations on Pregnancy, Parturition, and Postnatal Behavior in the Bottlenose Dolphin. J. Mammal. 1951, 32, 251-266. [CrossRef]

34. Mann, J. Individual differences in bottlenose dolphin infants. Fam. Sys. 1997, 4, 34-48.

35. Howells, E.M.; Reif, J.S.; Bechdel, S.E.; Murdoch, M.E.; Bossart, G.D.; McCulloch, S.D.; Mazzoil, M.S. A Novel Case of NonOffspring Adoption in a Free-Ranging Atlantic Bottlenose Dolphin (Tursiops truncatus) Inhabiting the Indian River La-goon, Florida. Aqua. Mamm. 2009, 35, 43-47. [CrossRef]

36. Kogi, K.; Hishii, T.; Imamura, A.; Iwatani, T.; Dudzinski, K.M. Demographic Parameters of Indo-Pacific Bottlenose Dolphins (Tursiops aduncus) Around Mikura Island, Japan. Mar. Mammal Sci. 2004, 20, 510-526. [CrossRef]

37. Dudzinski, K. Communication and Behavior in the Atlantic Spotted Dolphins (Stenella frontalis): Relationships between Vocal and Behavioral Activities. Ph.D. Thesis, Texas A\&M University, College Station, TX, USA, August 1996. Available online: https://www.researchgate.net/profile/Kathleen-Dudzinski/publication/35768063_Communication_and_behavior_in_the_ Atlan-tic_spotted_dolphins_Stenella_frontalis_relationships_between_vocal_and_behavioral_activities/links/5421ca190cf261 20b7a00a4d/Communication-and-behavior-in-the-Atlantic-spotted-dolphins-Stenella-frontalis-relationships-between-vocaland-behavioral-activities.pdf (accessed on 24 March 2021).

38. Harvey, B.N. The Nature of Social Relationships in Bottlenose Dolphins (Tursiops truncatus): Associations and the Role of Afiliative, Agonistic, and Socio-Sexual Behaviors. Master's Thesis, University of Southern Mississippi, Hattiesburg, MS, USA, 2015. Available online: https:/ /aquila.usm.edu/cgi/viewcontent.cgi?referer=https:// scholar.google.com/\&httpsredir=1\& article $=1131 \&$ context $=$ masters_theses (accessed on 24 March 2021).

39. Haidet, K.K.; Tate, J.; Divirgilio-Thomas, D.; Kolanowski, A.; Happ, M.B. Methods to improve reliability of video-recorded behavioral data. Res. Nurs. Health 2009, 32, 465-474. [CrossRef]

40. Lauderdale, L.K.; Miller, L.J. Common bottlenose dolphin (Tursiops truncatus) problem solving strategies in response to a novel interactive apparatus. Behav. Proc. 2019, 169, 103990. [CrossRef] [PubMed]

41. Lauderdale, L.K.; Miller, L.J. Efficacy of an interactive apparatus as environmental enrichment for common bottlenose dolphins (Tursiops truncatus). Anim. Welf 2020, 29, 379-386. [CrossRef]

42. Cairns, S.J.; Schwager, S.J. A comparison of association indices. Anim. Behav. 1987, 35, 1454-1469. [CrossRef]

43. Dugard, P.; File, P.; Todman, J.; Todman, J.B. Single-Case and Small-n Experimental Designs: A Practical Guide to Randomization Tests, 2nd ed.; Routledge: London, UK, 2012.

44. Kratochwill, T.R. Single Subject Research: Strategies for Evaluating Change, 1st ed.; Academic Press: Cambridge, MA, USA, 2013.

45. Ruiz, C.U.; Sánchez, A.; Maldonado, F.G. Social and individual behavior of a group of bottlenose dolphins (Tursiops truncatus) in open and closed facilities. Vet. Mex. 2009, 40, 381-387.

46. Paulos, R.D.; Trone, M.; Kuczaj, S.A. Play in wild and captive cetaceans. Int. J. Comp. Psychol. 2010, 23, 701-722.

47. Würsig, B.E.; Würsig, M.E. Behavior and ecology of the bottlenose dolphin, Tursiops truncatus, in the South Atlantic. Fish. Bull. 1979, 77, 399-412.

48. Cockcroft, V.G.; Ross, G.J.; Peddemors, V.M. Bottlenose dolphin Tursiops truncatus distribution in Natal's coastal waters. Sou. Afri. J. Mar. Sci. 1990, 9, 1-10. [CrossRef]

49. Caldwell, D.K.; Caldwell, M.C. The World of the Bottlenose Dolphin, 1st ed.; Lippencott: Philadelphia, PA, USA, 1972.

50. Clegg, I.; Van Elk, C.; Delfour, F. Applying welfare science to bottlenose dolphins (Tursiops truncatus). Anim. Welf. 2017, 26, 165-176. [CrossRef]

51. Mann, J.; Smuts, B. Behavioral development in wild bottlenose dolphin newborns (Tursiops sp.). Behaviour 1999, 136, 529-566.

52. Gibson, Q.A.; Mann, J. The size, composition and function of wild bottlenose dolphin (Tursiops sp.) mother-calf groups in Shark Bay, Australia. Anim. Behav. 2008, 76, 389-405. [CrossRef] 
53. Stanton, M.A.; Gibson, Q.A.; Mann, J. When mum's away: A study of mother and calf ego networks during separations in wild bottlenose dolphins (Tursiops sp.). Anim. Behav. 2011, 82, 405-412. [CrossRef]

54. Krzyszczyk, E.; Patterson, E.M.; Stanton, M.A.; Mann, J. The transition to independence: Sex differences in social and behavioural development of wild bottlenose dolphins. Anim. Behav. 2017, 129, 43-59. [CrossRef]

55. Hamilton, W.D. The genetical evolution of social behavior. J. Theor. Biol. 1964, 7, 17-52. [CrossRef]

56. Pope, T.R. Reproductive success increases with degree of kinship in cooperative coalitions of female red howler monkeys (Alouatta seniculus). Behav. Ecol. Socio. Biol. 2000, 48, 253-267. [CrossRef]

57. Silk, J.B. Kin Selection in Primate Groups. Int. J. Primatol. 2002, 23, 849-875. [CrossRef]

58. Duffield, D.; Wells, R.S. The combined application of chromosome, protein and molecular data for the investigation of social unit structure and dynamics in Tursiops truncatus. Rep. Int. Whal. Comm. 1991, 13, 155-169.

59. Möller, L.M.; Beheregaray, L.B.; Allen, S.; Harcourt, R.G. Association patterns and kinship in female Indo-Pacific bottlenose dolphins (Tursiops aduncus) of southeastern Australia. Behav. Ecol. Sociobiol. 2006, 61, 109-117. [CrossRef]

60. Gibson, Q.A.; Mann, J. Early social development in wild bottlenose dolphins: Sex differences, individual variation and maternal influence. Anim. Behav. 2008, 76, 375-387. [CrossRef]

61. Eastcott, A.; Dickinson, T. Underwater observations of the suckling and social behavior of a newborn bottlenosed dolphin (Tusiops truncatus). Aqua. Mamm. 1987, 13, 51-56.

62. Clegg, I.L.K.; Rödel, H.G.; Cellier, M.; Vink, D.; Michaud, I.; Mercera, B.; Böye, M.; Hausberger, M.; Lemasson, A.; Delfour, F. Schedule of human-controlled periods structures bottlenose dolphin (Tursiops truncatus) behavior in their free-time. J. Comp. Psychol. 2017, 131, 214-224. [CrossRef] [PubMed]

63. Serres, A.; Robeck, T.; Deng, X.; Steinman, K.; Hao, Y.; Wang, D. Social, Reproductive and Contextual Influences on Fecal Glucocorticoid Metabolites in Captive Yangtze Finless Porpoises (Neophocaena asiaeorientalis asiaeorientalis) and Bottlenose Dolphins (Tursiops truncatus). J. Zool. Bot. Gard. 2020, 1, 24-41. [CrossRef]

64. Clegg, I.L.; Rödel, H.G.; Delfour, F. Bottlenose dolphins engaging in more social affiliative behaviour judge ambiguous cues more optimistically. Behav. Brain Res. 2017, 322, 115-122. [CrossRef] [PubMed] 